\title{
Upscaling methods used in ex ante life cycle assessment of emerging technologies: a review
}

\author{
Natalya Tsoy ${ }^{1}$ (D) $\cdot$ Bernhard Steubing $^{1} \cdot$ Coen van der Giesen ${ }^{1} \cdot$ Jeroen Guinée ${ }^{1}$
}

Received: 22 January 2020 / Accepted: 23 July 2020 / Published online: 6 August 2020

(C) The Author(s) 2020

\begin{abstract}
Purpose The objective of this paper was to provide LCA practitioners with recommendations and a framework for upscaling emerging technologies by reviewing upscaling methods applied so far in ex ante life cycle assessment (LCA).

Methods Web of Science was searched for articles published between 1990 and 2019 (April) using different variations of the term "ex ante LCA" as keywords. Suitable studies were reviewed to understand the key characteristics and main methodological principles of upscaling methods.

Results and discussion A total of 18 studies were selected for literature review. Review results showed that most studies reported what a hypothetical upscaled technology would look like in the future. All studies described how they estimated data; they applied different data estimation methods, using process simulation, manual calculations, molecular structure models (MSMs) and proxies. Since the review results showed that most ex ante LCA studies followed similar upscaling steps, we developed a framework for the upscaling of emerging technologies in ex ante LCA consisting of three main steps: (1) projected technology scenario definition, (2) preparation of a projected LCA flowchart, and (3) projected data estimation. Finally, a decision tree was developed based on the review results that provides recommendations for LCA practitioners regarding the upscaling procedure in ex ante LCA.

Conclusions Our findings can be useful for LCA practitioners aiming at upscaling in ex ante LCA. We provide an overview of upscaling methods used in ex ante LCA and introduce a framework describing the steps involved in the upscaling process and a decision tree recommending an up-scaling procedure. The results show that in theory all data estimation methods described in this paper can be applied to estimate material flows, energy flows, and elementary flows (emissions and natural resource use). Finally, since different kinds of expertise are required for upscaling in ex ante LCA, we recommend that technology experts from different fields are involved in performing ex ante LCA, e.g., technology developers, LCA practitioners, and engineers.
\end{abstract}

Keywords Life cycle assessment $\cdot$ Ex ante LCA $\cdot$ Upscaling $\cdot$ Emerging technology $\cdot$ New technology $\cdot$ Review

\section{Introduction}

The environmental assessment of emerging technologies at an early phase of their development has received increasing

Responsible editor: Ivan Muñoz

Electronic supplementary material The online version of this article (https://doi.org/10.1007/s11367-020-01796-8) contains supplementary material, which is available to authorized users.

Natalya Tsoy

n.tsoy@cml.leidenuniv.nl

1 Institute of Environmental Sciences (CML), Leiden University, Einsteinweg 2, 2333, CC Leiden, the Netherlands attention over the past few years (Wender et al. 2014). An increasing number of novel technologies are claimed to be environmentally sustainable (Pallas et al. 2018), while such claims need to be proven by carrying out, for example, early on environmental assessments. Determining possible environmental impacts at an early stage of research and development (R\&D) allows reorienting technology development towards improved environmental performance levels at relatively low costs. In contrast, changes are difficult to implement and will entail much higher costs when a technology is close to commercialization. However, this implies a change from ex-post to ex ante environmental assessments (Cucurachi et al. 2018).

Life cycle assessment (LCA) has been widely recognized as a valuable framework for the assessment of technologies (Hellweg and Canals 2014). Typically, LCA is carried out for 
existing industrial scale technologies, for which industrial scale data is readily available. Application of such ex-post LCA to new technologies is problematic since their system specifications at the industrial scale are highly uncertain and large-scale process data is generally lacking. To fill this gap, ex ante LCA has evolved in recent years, aiming to assess emerging technologies at an early stage of development by exploring, among others, possible scenarios of their future industrial scale implementation (Cucurachi et al. 2018).

This review paper focuses on studies that performed ex ante LCA. Van der Giesen et al. (2020) define ex ante LCA as "performing an environmental life cycle assessment of a new technology before it is commercially implemented in order to guide R\&D decisions to make this new technology environmentally competitive as compared to the incumbent technology mix." They argue that the differences between ex ante and ex-post LCA are not so much in the general framework of LCA but rather in the implementation of selected phases and steps, including the definition of the intended application of emerging technologies, the definition of the functional unit, the drafting of the flowchart, and the estimation of future projection of the technology, related data, etc. A key property of this implementation is the "unknown" that ex ante assessments have to deal with: partly or fully unknown applications, systems, flowchart, and data.

Various LCA modes exist (Guinée et al. 2018), and several of them have been used to assess new technology systems, including prospective LCA, ex ante or anticipatory LCA, dynamic LCA, and consequential LCA. The differences between these modes have already been extensively discussed (Cucurachi et al. (2018), Buyle et al. (2019), Van der Giesen et al. (2020), Guinée et al. 2018) and are outside the scope of this article. We here only focus on the ex ante and anticipatory modes of LCA since only these specifically focus on dealing with the "unknowns" of emerging technology systems in our view. From here onwards, we will refer to them as "ex ante LCA" studies.

Ex ante LCA of emerging technologies is associated with various challenges, such as a clear definition of the function of a future system, uncertainties, and the upscaling of the LCA data (Hetherington et al. 2014). Furthermore, both the foreground as well as the background systems in life cycle inventory (LCI) databases may have to be modified to obtain a meaningful representation of the emerging technology in its future context (Arvidsson et al. 2018). Our paper particularly focuses on the challenge of upscaling the novel and unknown part of an emerging technology in the foreground system for ex ante LCA.

An important aspect when discussing upscaling of technologies is a technology's TRL (technology readiness level). The TRL is a method for assessing a technology's maturity, ranging from level 1, observation of basic principles, to level 9, the fully evolved operational system (Mankins 1995; Gavankar et al. 2015). The European Association of Research and
Technology (EARTO) (2014) linked TRL to manufacturability (Fig. 1).

In ex ante LCA, the system specifications and data of new technologies often originate from laboratory (lab-scale) implementations (Fig. 1: TRL 3-5) or from pilot-plant (pilot-scale) implementations (Fig. 1: TRL 6-8). The data derived from these early realizations of a technology (lab-scale, pilot-scale) can generally not be used in the assessment of the future technology as it is far from representative of industrial scale data (Fig. 1: TRL 9). Industrial scale processes may significantly differ from lab-scale and pilot-scale processes regarding the equipment and technologies used and regarding performance data (Piccinno et al. 2018; González-García et al. 2018a,b; Salas et al. 2018). In particular, the industrial processes are generally much more efficient than the laboratoryscale or pilot-scale processes due to the implementation of complex equipment and sophisticated features, e.g. heat recovery systems and waste recycling loops. To perform meaningful LCAs on emerging technologies, the lack of industrial scale data can be resolved by upscaling the lab-scale or pilotscale systems and data to projected industrial scale levels, with or without using explicit methods and/or scenarios.

Upscaling in ex ante LCA has not been extensively explored in literature so far, although various upscaling methods have been used in ex ante LCA studies. Some studies developed frameworks and systematic procedures for upscaling. For instance, Shibasaki et al. (2006) introduced a systematic approach for upscaling pilot-plant processes to industrial plant processes. In their work, they presented technical aspects which should be considered in the upscaling process. Piccinno et al. (2016) proposed a framework for upscaling common processes in wet chemistry from lab scale to industrial scale. This framework comprises calculation procedures and qualitative guidance for upscaling based on literature and expert consultation. Simon et al. (2016) introduced a framework for the estimation of industrial process data based on the results of laboratory experiments. In order to demonstrate how the framework works, the authors applied this framework to upscale nanofiber electrospinning for Li-ion battery cathode applications. Finally, a few studies conducted a review on LCA of emerging technologies and touched upon the topic of upscaling in LCA (Buyle et al. 2019; Moni et al. 2020; Thonemann et al. 2020).

However, little research has been done on the differences and similarities between the key characteristics and methodological principles of upscaling methods for emerging technologies. To fill this research gap, we conducted a review of ex ante LCA studies applying upscaling methods. The objectives of our work were to develop a framework describing the upscaling steps based on the review results and to provide recommendations for LCA practitioners regarding an upscaling procedure. With our review, we aimed to answer the following research questions: 


\begin{tabular}{|c|c|c|c|c|c|c|c|c|}
\hline 1 & 2 & 3 & 4 & 5 & 6 & 7 & 8 & 9 \\
\hline $\begin{array}{c}\text { Basic principles } \\
\text { observed }\end{array}$ & $\begin{array}{l}\text { Technology } \\
\text { concept } \\
\text { formulated }\end{array}$ & $\begin{array}{c}\text { First assessment } \\
\text { of feasibility of } \\
\text { the concept \& } \\
\text { technologies }\end{array}$ & $\begin{array}{l}\text { Validation of } \\
\text { integrated } \\
\text { prototype in lab } \\
\text { environment }\end{array}$ & $\begin{array}{l}\text { Testing of the } \\
\text { prototype in } \\
\text { a user } \\
\text { environment }\end{array}$ & $\begin{array}{l}\text { Pre-production } \\
\text { of the product }\end{array}$ & $\begin{array}{l}\text { Low scale pilot } \\
\text { production } \\
\text { demonstrated }\end{array}$ & $\begin{array}{l}\text { Manufacturing } \\
\text { fully tested, } \\
\text { validated and } \\
\text { qualified }\end{array}$ & $\begin{array}{l}\text { Production \& } \\
\text { product are fully } \\
\text { operational }\end{array}$ \\
\hline Inve & & \multicolumn{2}{|c|}{ Concept validation } & $\begin{array}{l}\text { Prototyping } \\
\text { \& incubation }\end{array}$ & \multicolumn{2}{|c|}{$\begin{array}{l}\text { Pilot production } \\
\text { \& demonstration }\end{array}$} & $\begin{array}{l}\text { Initial market } \\
\text { introduction }\end{array}$ & $\begin{array}{c}\text { Market } \\
\text { expansion }\end{array}$ \\
\hline
\end{tabular}

Fig. 1 European Association of Research and Technology (EARTO) reading on the TRL scales (EARTO 2014)

1. Which upscaling methods have already been applied in ex ante LCA, and what are their key characteristics and methodological principles?

2. What steps are involved in the upscaling of emerging technologies in ex ante LCA?

3. Which recommendations can be given to practitioners of ex ante LCA regarding upscaling?

\section{Methods}

\subsection{Literature selection}

To answer the research questions, a literature search and review was done using Web of Science for studies published from 1990 to 2019 (April). Different variations of the term "ex ante LCA" were used as keywords: TOPIC: ("anticipatory life cycle assessment") OR TOPIC: ("anticipatory life cycle analysis") OR TOPIC: ("anticipatory LCA") OR TOPIC: ("prospective life cycle assessment") OR TOPIC: ("prospective life cycle analysis") OR TOPIC: ("prospective LCA") OR TOPIC: ("ex-ante life cycle assessment") OR TOPIC: ("exante life cycle analysis") OR TOPIC: ("ex-ante LCA") OR TOPIC: ("life cycle assessment" AND "up scal*") OR TOPIC: ("life cycle analysis" AND "up scal*”) OR TOPIC: (LCA AND "up scal*") OR TOPIC: ("life cycle assessment" AND "scal* up") OR TOPIC: ("life cycle analysis" AND "scal* up") OR TOPIC: (LCA AND "scal* up"). These keywords were searched in the titles, the abstracts, and the author keywords of the articles. The titles and the abstracts of publications found with these keywords were screened, and studies meeting the following exclusion criteria were excluded:

- Studies that did not perform LCA

- Review papers

- LCA studies that developed scenarios for future development of an existing technology but did not upscale a technology

- Studies that performed laboratory LCA but did not perform upscaling

- LCA studies that upscaled LCIA (life cycle impact assessment) results only without explicit upscaling of inventory processes and process data
- Ex ante LCA studies that did not clearly describe the upscaling procedure applied in a case study or did not describe such a procedure at all.

Studies meeting all criteria were further reviewed.

\subsection{Literature review}

We defined the two sets of criteria and reviewed all the included studies against these criteria to obtain a better understanding of the upscaling methods applied:

1. Criteria identifying the key characteristics of upscaling methods:

a. What technology was upscaled?

b. What was the starting scale and to which scale was a technology upscaled? Here we will group the studies applying upscaling into 4 categories:

i. From lab scale to pilot scale

ii. From lab scale to industrial scale

iii. From pilot scale to industrial scale

iv. From lab and pilot scales to industrial scale

c. Did the upscaling method provide results for energy flows, material flows, and elementary flows (emissions and natural resource use) or only for one or two of these?

2. Criteria identifying the main methodological principles of upscaling methods:

a. Was a hypothetical upscaled technology described?

b. Were upscaling methods based on different estimation or calculation principles?

c. What data was required for the applied upscaling methods?

In Section 4 we introduced a framework describing the upscaling steps in ex ante LCA. In addition, we discussed to what extent the included ex ante LCA studies explicitly dealt with the steps introduced in the framework. Finally, based on the review results, we developed a decision tree that provides recommendations for LCA practitioners regarding upscaling for ex ante LCA. 


\section{Results}

Of 184 studies identified initially (Online Recourse 2), screening resulted in 18 studies that met all the criteria. In order to answer research question 1, "Which up-scaling methods have already been applied in ex-ante LCA, and what are their key characteristics and methodological principles?", upscaling methods used in the included ex ante LCA studies were reviewed using the two sets of criteria defined in Section 2.2: (1) criteria identifying the key characteristics of upscaling methods and (2) criteria identifying the main methodological principles of upscaling methods. Section 3.1 presents the key characteristics of the applied upscaling methods, and Section 3.2 shows the results for their methodological principles.

\subsection{Key characteristics of upscaling methods}

Table 1 shows the key characteristics of upscaling methods applied in 18 ex ante LCA studies. To be more specific, Table 1 describes the kind of technology that each study upscaled, the starting and end scales for the upscaling, and the results that were calculated after upscaling (energy inputs and/or outputs, material inputs and/or outputs, and elementary flows (emissions and natural resource use)).

The review results showed that studies upscaled different kinds of technologies from different application domains, such as chemistry, waste treatment, energy, food, and the building sector (Table 1 and Online Resource 2). Most studies upscaled chemical and waste treatment technologies (15 out of 18 studies) (Table 1 and Online Resource 2).

In general, most studies (11 out of 18) upscaled technologies from the lab to industrial scale (Table 1). All studies estimated energy and material inputs and outputs, but some studies did not report how they estimated elementary flows (natural resource use and/or emissions) (Table 1).

\subsection{Methodological principles of upscaling methods}

Two studies mentioned that LCA experts had discussions with technology experts about what the hypothetical upscaled technologies would look like (Villares et al. 2016; Schulze et al. 2018). Muñoz (2019) developed a scenario of a hypothetical upscaled technology as follows (pers. comm.): first, the LCA expert and the technology expert explored how the pilot-scale technology would differ from the upscaled industrial scale technology. Then, they determined how the pilot-scale processes should be modified, and by modifying the processes one by one, they concluded what the new technology could look like in the future in an upscaled form.

In 5 out of 18 studies, simulation software was used to obtain a process design of a hypothetical upscaled technology (Cossutta et al. 2017; Fernández-Dacosta et al. 2015; Mazzoni et al. 2019; Rinaldi et al. 2015; Khojasteh Salkuyeh et al. 2017). In 5 out of 18 studies, a simple conceptual process diagram was used to describe the process steps and equipment included in the hypothetical upscaled technology (GonzálezGarcía et al. 2018b; Muñoz et al. 2019; Piccinno et al. 2016; Piccinno et al. 2018; Simon et al. 2016). In 1 study (GonzálezGarcía et al. 2018a), a simple conceptual process diagram was used as well as simulation software for the specific design of equipment.

In 17 out of 18 studies, the authors provided a description of how they viewed the hypothetical upscaled technology, e.g., by describing assumptions about the upscaled technology and/or by describing the parts or processes of a new technology (Online resource 2).

In 9 out of 18 studies, the authors presented a full LCA flowchart of a hypothetical upscaled technology (Online resource 2). González-García et al. (2018a, b) showed how the conceptual process diagrams of the upscaled technology were converted to the LCA flowcharts. Other studies did not provide information on how the LCA flowchart was developed based on the simulation process design or conceptual process diagram.

All studies reported that they estimated data for each of the unit process defined in the LCA flowchart or in the simple conceptual process diagram. The review results revealed that data estimation methods used in the ex ante LCA studies were similar to the data estimation methods applied in ex-post LCA studies (Parvatker and Eckelman 2019):

1. Process simulation

2. Manual calculations

3. Molecular structure models (MSMs)

4. Use of proxy

The data estimation methods used in the included ex ante LCA studies were classified using the classification of data estimation methods introduced by Parvatker and Eckelman (2019). The included ex ante LCA studies estimated data for the separate unit processes defined in the LCA flowchart or simple process diagram and used a mix of data estimations methods in the upscaling of a new technology.

Process simulation includes all data estimation methods that involve the use of simulation software and databases. The review results show that 6 of 18 included studies performed process simulation using simulation software (Cossutta et al. 2017; Fernández-Dacosta et al. 2015; González-García et al. 2018a; Mazzoni et al. 2019; Rinaldi et al. 2015; Khojasteh Salkuyeh et al. 2017). They used labscale or pilot-scale operation parameters as inputs for the simulation software. Energy flows, material flows, and elementary flows were obtained as a result of calculations done with process simulation. 
Table 1 Key characteristics of upscaling methods applied in ex ante LCA

\begin{tabular}{|c|c|c|c|c|c|}
\hline \multirow[t]{2}{*}{ Study } & \multirow[t]{2}{*}{ Technology } & \multirow{2}{*}{$\begin{array}{l}\text { Upscaled from } \\
\rightarrow \text { to }\end{array}$} & \multicolumn{3}{|l|}{ Results } \\
\hline & & & $\begin{array}{l}\text { Energy inputs } \\
\text { and/or outputs }\end{array}$ & $\begin{array}{l}\text { Material inputs } \\
\text { and/or outputs }\end{array}$ & $\begin{array}{l}\text { Elementary } \\
\text { flows }^{\mathrm{a}}\end{array}$ \\
\hline $\begin{array}{l}\text { Arvidsson and } \\
\quad \text { Molander (2017) }\end{array}$ & Epitaxial graphene production & $\begin{array}{l}\text { Lab and pilot } \\
\quad \rightarrow \text { industrial }\end{array}$ & $\mathfrak{J}^{\mathrm{b}}$ & $\checkmark$ & $-c$ \\
\hline $\begin{array}{l}\text { Cossutta et al. } \\
\text { (2017) }\end{array}$ & Graphene production & $\begin{array}{l}\mathrm{Lab} \rightarrow \\
\quad \text { industrial }\end{array}$ & $\checkmark$ & $\checkmark$ & $\checkmark$ \\
\hline $\begin{array}{l}\text { Cuéllar-Franca } \\
\text { et al. (2016) }\end{array}$ & Production of ionic liquids for $\mathrm{CO}_{2}$ capture & $\begin{array}{l}\text { Lab } \rightarrow \\
\quad \text { industrial }\end{array}$ & $\checkmark$ & $\checkmark$ & - \\
\hline $\begin{array}{l}\text { Fernández-Dacosta } \\
\text { et al. (2015) }\end{array}$ & $\begin{array}{l}\text { Production of microbial community-based } \\
\text { polyhydroxyalkanoates (PHAs) from wastewater }\end{array}$ & $\begin{array}{l}\text { Lab and pilot } \\
\quad \rightarrow \text { industrial }\end{array}$ & $\checkmark$ & $\checkmark$ & $\checkmark$ \\
\hline $\begin{array}{l}\text { González-García } \\
\text { et al. (2018a) }\end{array}$ & Production of bio-succinic acid from apple pomace & $\begin{array}{l}\mathrm{Lab} \rightarrow \\
\quad \text { industrial }\end{array}$ & $\checkmark$ & $\checkmark$ & $\checkmark$ \\
\hline $\begin{array}{l}\text { González-García } \\
\text { et al. }(2018 b)\end{array}$ & Bio-ethanol and xylooligosaccharides joint production & $\begin{array}{l}\text { Lab } \rightarrow \\
\quad \text { industrial }\end{array}$ & $\checkmark$ & $\checkmark$ & $\checkmark$ \\
\hline $\begin{array}{l}\text { Mattick et al. } \\
\text { (2015) }\end{array}$ & In vitro biomass production for cultured meat & $\begin{array}{l}\text { Lab } \rightarrow \\
\quad \text { industrial }\end{array}$ & $\checkmark$ & $\checkmark$ & $\checkmark$ \\
\hline $\begin{array}{l}\text { Mazzoni et al. } \\
\text { (2019) }\end{array}$ & Catalytic Biorefining of Ethanol from Wine Waste & $\begin{array}{l}\text { Lab } \rightarrow \\
\quad \text { industrial }\end{array}$ & $\checkmark$ & $\checkmark$ & $\checkmark$ \\
\hline Muñoz et al. (2019) & Solar-assisted heat pump (SHP) and waste water treatment & $\begin{array}{l}\text { Pilot } \rightarrow \\
\text { industrial }\end{array}$ & $\checkmark$ & $\checkmark$ & $\checkmark$ \\
\hline $\begin{array}{l}\text { Piccinno et al. } \\
\qquad(2016)^{\mathrm{d}}\end{array}$ & $\begin{array}{l}\text { Heated liquid phase batch reactions and certain isolation, } \\
\text { purification and processing steps }\end{array}$ & $\begin{array}{l}\text { Lab } \rightarrow \\
\quad \text { industrial }\end{array}$ & $\checkmark$ & $\checkmark$ & $\checkmark$ \\
\hline $\begin{array}{l}\text { Piccinno et al. } \\
\text { (2018) }\end{array}$ & Nanocellulose production using carrot waste & $\begin{array}{l}\mathrm{Lab} \rightarrow \\
\quad \text { industrial }\end{array}$ & $\checkmark$ & $\checkmark$ & $\checkmark$ \\
\hline Rinaldi et al. (2015) & Pyrolysis gasification of automotive shredder residue & $\begin{array}{l}\text { Pilot } \rightarrow \\
\quad \text { industrial }\end{array}$ & $\checkmark$ & $\checkmark$ & $\checkmark$ \\
\hline Salas et al. (2018) & Production of geopolymer concrete & $\begin{array}{l}\text { Lab } \rightarrow \\
\quad \text { industrial }\end{array}$ & $\checkmark$ & $\checkmark$ & - \\
\hline $\begin{array}{l}\text { Khojasteh } \\
\text { Salkuyeh et al. } \\
\text { (2017) }\end{array}$ & $\begin{array}{l}\text { Hydrogen production from natural gas: Syngas chemical } \\
\text { looping (SCL) and chemical looping reforming (CLR) }\end{array}$ & $\begin{array}{l}\text { Not mentioned } \\
\rightarrow \text { industrial }\end{array}$ & $\checkmark$ & $\checkmark$ & $\checkmark$ \\
\hline $\begin{array}{l}\text { Sampaio et al. } \\
\quad(2017)\end{array}$ & Gelatin production from tilapia residues & Lab $\rightarrow$ pilot & $\checkmark$ & $\checkmark$ & $\checkmark$ \\
\hline $\begin{array}{l}\text { Schulze et al. } \\
\text { (2018) }\end{array}$ & $\begin{array}{l}\text { Rare Earth Extraction from NdFeB Magnet Scrap Using } \\
\text { Molten Salt Electrolysis }\end{array}$ & $\begin{array}{l}\text { Lab } \rightarrow \\
\quad \text { industrial }\end{array}$ & $\checkmark$ & $\checkmark$ & - \\
\hline Simon et al. (2016) & $\begin{array}{l}\text { Production of nanofibers for lithium iron phosphate cathode } \\
\text { applications }\end{array}$ & $\begin{array}{l}\text { Lab } \rightarrow \\
\quad \text { industrial }\end{array}$ & $\checkmark$ & $\checkmark$ & $\checkmark$ \\
\hline $\begin{array}{l}\text { Villares et al. } \\
\text { (2016) }\end{array}$ & Metal recovery from e-waste using bioleaching & Lab $\rightarrow$ pilot & $\checkmark$ & $\checkmark$ & $\checkmark$ \\
\hline
\end{tabular}

${ }^{a}$ Elementary flows = emissions and natural resource use (land use was not included in the review criteria)

b “ $\checkmark$ " indicates that a study reported on the estimation of energy inputs and/or outputs, material inputs and/ or outputs, and elementary flows

c “.” indicates that a study did not report on the estimation of energy inputs and/ or outputs, material inputs and/ or outputs, and elementary flows

${ }^{\mathrm{d}}$ The authors presented an upscaling framework for chemical processes and applied the upscaling framework to a fictional example of a technology

Manual calculations include all calculations done manually with the help of mathematical and physical equations, stoichiometric relationships, scaling factors, etc. Most studies (10 out of 18) performed manual calculations, although these were based on different calculation principles. For example, Piccinno et al. (2016, 2018) used basic mathematical and physical equations to calculate energy flows, material flows, and emissions. Some studies used stoichiometric calculations (e.g. Cuéllar-Franca et al. 2016) to estimate material inputs and outputs and emissions, while other studies used linear scaling of lab data to estimate material flows and elementary flows at larger scales (Piccinno et al. 2016; Sampaio et al. 2017).

Molecular structure models (MSMs) are models that are based on neural networks (Hornik et al. 1989) and can be used to calculate key LCI parameters and impact results using the molecular structure of a chemical (Wernet et al. 2009). One of the 18 included studies used MSMs for data estimation (Mazzoni et al. 2019). MSMs were used to estimate resource consumption and environmental impacts of the catalyst production. 
Proxies can be used to approximate data by using information from a similar already existing technology that shows high resemblance with the new technology. In this review, proxy refers to an existing technology that most closely resembles the hypothetical upscaled technology. Proxies were used for data estimation in 7 out of 18 studies (Mattick et al. 2015; Simon et al. 2016; Villares et al. 2016; Sampaio et al. 2017; Salas et al. 2018; Schulze et al. 2018; Muñoz et al. 2019). They retrieved proxy data from various sources, such as LCI databases (Muñoz et al. 2019; Villares et al. 2016), the literature and engineering case studies (Schulze et al. 2018; Villares et al. 2016), online catalogs of the machines (Sampaio et al. 2017; Salas et al. 2018), and expert consultation provided by technology developers (Simon et al. 2016). Energy flows, material flows, and elementary flows of the new technologies were approximated by using data of a similar existing technology.

Table 2 shows the review results of data estimation in the ex ante LCA studies. In Table 2, the columns "Energy inputs and/or outputs," "Material inputs and/or outputs," and "Elementary flows" (under "Data estimation") show the methods which the studies used to estimate energy flows, material flows, and elementary flows; the estimation or calculation principles of those methods; and the data which were used for the data estimation (see details in Online Resource 1). It should be noted that the studies did not estimate data for a new technology as a whole but for its separate unit processes. That is why the table shows that some studies used a mix of data estimation methods to estimate energy flows, material flows, or elementary flows.

\section{Discussion}

Assessment of emerging technologies at an early stage of $\mathrm{R} \& \mathrm{D}$ is crucial, as it allows for reorienting technology development towards decreased environmental burdens at lower costs. Ex ante LCA is a tool that has emerged recently and started to be widely used by LCA practitioners in the assessment of novel technologies. While existing technologies, for which data is readily available, are commonly assessed with ex-post LCA, application of ex-post LCA to emerging technologies is challenging, as the future environmental impacts of such technologies need to be assessed when the technologies are still at the lab or pilot scale, and hence system specifications and data at industrial scale are not yet available. In order to overcome these challenges, upscaling of technologies can be performed in ex ante LCA. In this paper, we reviewed the differences and similarities between the key characteristics and methodological principles of upscaling methods applied so far in ex ante LCA.

\subsection{A framework describing the steps involved in the upscaling of emerging technologies}

The review results show that most of the included studies followed similar upscaling steps. Based on these results, we developed a framework that aims to distinguish between the steps of upscaling that are predominantly based on technology expertise and the steps that are predominantly based on LCA knowledge. The resulting framework is applicable for upscaling of technologies in different application domains. Below, we give a brief overview of technology development and ex ante LCA, and then we introduce a framework for upscaling a new technology in ex ante LCA.

To the best of our knowledge, the term "upscaling method" has not yet been defined in the field of ex ante LCA in literature. Therefore, we drafted a definition for "upscaling method" and present it below in Section 4.1.2.

\subsubsection{Technology development and ex ante LCA}

Technology development starts with the concept development of the idea for a novel technology (TRL 1-2). In this process, technology experts may generate several scenarios. Before being able to develop an LCA model of an emerging technology system, we need to know how that system will look like in future. As technology developers are the experts in projecting scenarios of such future systems, they are the first ones to be consulted. Their scenarios particularly focus on how the specific elements of the emerging technology are expected to develop in future. The scenarios are a projection of what the technology experts expect that a technology at a low TRL will look like at a given higher TRL in future. We will refer to this as "projected technology scenarios." We use the plural ("scenarios") form deliberately, because future projections of the technology represent explorations of possible futures rather than a prediction of one particular future. Next, the technology experts select a couple of scenarios that seem to be the most promising and feasible among other scenarios and develop laboratory set-ups for these scenarios (TRL 3-5). Next, the technology experts theoretically upscale the novel technology system in one or more promising scenarios to higher TRLs (TRL 69). In some cases, technology experts may build pilot-scale technology (TRL 6-8) and then theoretically upscale it to industrial scale.

Ex ante LCA studies lacking the involvement of technology experts are of limited value unless the LCA expert is also a recognized technology expert. The latter is possible although rarely the case. Note that our view on the role of technology experts is founded on our definition of ex ante LCA as provided in the Introduction of this article. 
Table 2 Data estimation methods used in upscaling methods applied in ex ante LCA

Data estimation

\begin{tabular}{|c|c|c|c|}
\hline & Energy inputs and/or outputs & Material inputs and/or outputs & Elementary flows* \\
\hline Arvidsson and & $\mathbf{M}^{*}:$ Manual calculations & M: (1) Manual calculations & Not reported $^{\mathrm{a}}$ \\
\hline Molander (2017) & $\begin{array}{l}\text { P\&D*: Calculations using thermodynamic } \\
\text { equations; Linear scaling: assumption } \\
\text { that electricity consumption at pilot scale } \\
\text { is the same as at industrial scale } \\
\text { (worst-case scenario) }\end{array}$ & $\begin{array}{l}\text { P\&D: (1) Assumption on possible indus- } \\
\text { trial parameters (expert opinion) and } \\
\text { their use in calculations }\end{array}$ & \\
\hline $\begin{array}{l}\text { Cossutta et al. } \\
\text { (2017) }\end{array}$ & $\begin{array}{l}\text { M: Process simulation }{ }^{\mathrm{b}} \\
\text { P\&D: The use of the process simulation re }\end{array}$ & esults for data estimation & \\
\hline
\end{tabular}

Cuéllar-Franca

et al. (2016)

Fernández-Dacosta et al. (2015)

González-García et al. (2018a)

González-García et al. (2018b)

Mattick et al. (2015)

Mazzoni et al. (2019)

\section{M: Manual calculations \\ P\&D: Calculations using the heat of} formation of reactants and products and then multiplying by empirical factors

M: Manual calculations

P\&D: Stoichiometry and the use of (from literature)

M: Process simulation ${ }^{\mathrm{b}}$

P\&D: The use of the process simulation results for data estimation

M: (1) Manual calculations. (2) Process simulation ${ }^{\mathrm{b}}$ process simulation results for data estimation

M: Manual calculations

P\&D: Use of thermodynamic equations, average values and estimations (expert opinion, literature)

M: Use of proxy

P\&D: Calculations using operating parameters of a similar existing technology

M: Process simulation ${ }^{\mathrm{b}}$

P\&D: The use of the process simulation results for data estimation
Not reported

P\&D: (1) The use of thermodynamic equations, average values and estimations (expert opinion, literature). (2) The use of the

M: (1) Process simulation ${ }^{\mathrm{b}}$. (2) molecular structure models

P\&D: (1) The use of the process simulation results for data estimation. 2) The use of FineChem tool (ETH Zurich n.d.)

Muñoz et al. (2019) M: (1) The use of proxy. (2) Manual calculations

P\&D: (1) Assumption that electricity consumption is the same as that of a similar industrial plant. (2) Calculations using experimental small-scale (pilot-plant) data
M: (1) The use of proxy. (2) Manual calculations

P\&D: (1) Assumption of possible industrial parameters (from literature) and their use in calculations. (2) Mass balance calculations based on stoichiometry and empirical relationships of parameters
Piccinno et al. (2016)

Piccinno et al. (2018)

Rinaldi et al. (2015)

Salas et al. (2018)

Khojasteh Salkuyeh et al. (2017)

Sampaio et al. (2017)

M: Manual calculations

P\&D: Use of thermodynamic equations, scaling factors, average values and estimations (expert opinion, literature)

M: Manual calculations

P\&D: Use of thermodynamic equations, average values and estimations (expert opinion, literature)

M: Manual calculations

P\&D: Mass balance calculations based on stoichiometry and empirical relationships of parameters

M: Process simulation ${ }^{\mathrm{b}}$

P\&D: The use of the process simulation results for data estimation

M: (1) The use of proxy. (2) Manual cal- M: Manual calculations culations

P\&D: (1) Calculations using technical

P\&D: Calculations using experimental

Not reported specifications for machine. (2) Calculations using thermodynamic equations

M: Process simulation ${ }^{\mathrm{b}}$

P\&D: The use of the process simulation results for data estimation

M: Use of proxy

P\&D: Calculations using technical specifications for machine (from online catalogs)
M: Manual calculations

P\&D: Linear scaling: assumption that the amount of reagents increases linearly from the laboratory scale to the pilot scale
M: Manual calculations

P\&D: Linear scaling: assumption that the amount of effluent loads increases linearly from the laboratory scale to the pilot scale 
Table 2 (continued)

\begin{tabular}{|c|c|c|c|}
\hline & \multicolumn{3}{|l|}{ Data estimation } \\
\hline & Energy inputs and/or outputs & Material inputs and/or outputs & Elementary flows* \\
\hline $\begin{array}{l}\text { Schulze et al. } \\
\text { (2018) }\end{array}$ & $\begin{array}{l}\text { M: Use of proxy } \\
\text { P\&D: 1) Assumption that electricity use is } \\
\text { the same as that of a similar technology } \\
\text { (from literature) }\end{array}$ & $\begin{array}{l}\text { M: Use of proxy } \\
\text { P\&D: Assumption that material inputs are } \\
\text { the same as those of a similar } \\
\text { technology (from literature) }\end{array}$ & Not reported \\
\hline Simon et al. (2016) & $\begin{array}{l}\text { M: Use of proxy } \\
\text { P\&D: Calculations using technical } \\
\text { specifications for machine (from } \\
\text { machine developers) }\end{array}$ & $\begin{array}{l}\text { M: Manual calculations } \\
\text { P\&D: Calculations using experimental } \\
\text { lab data }\end{array}$ & $\begin{array}{l}\text { M: Use of proxy } \\
\text { P\&D: Use of emissions data (from } \\
\quad \text { literature) }\end{array}$ \\
\hline $\begin{array}{l}\text { Villares et al. } \\
\text { (2016) }\end{array}$ & $\begin{array}{l}\text { M: Use of proxy } \\
\text { P\&D: Use of adapted ecoinvent } \\
\text { processes; Calculations using operating } \\
\text { parameters of a similar existing } \\
\text { technology (from engineering case } \\
\text { study) }\end{array}$ & $\begin{array}{l}\text { M: Use of proxy } \\
\text { P\&D: Assumption that material inputs are } \\
\text { the same as those of a similar existing } \\
\text { technology (from engineering case } \\
\text { study) }\end{array}$ & $\begin{array}{l}\text { M: Use of proxy } \\
\text { P\&D: 1) Use of ecoinvent processes; } \\
\text { Assumption that resource inputs are the } \\
\text { same as those of a similar existing } \\
\text { technology (from engineering case } \\
\text { study). }\end{array}$ \\
\hline
\end{tabular}

*Elementary flows $=$ emissions and natural resource use, $\mathrm{M}=$ method, $\mathrm{P} \& \mathrm{D}=$ calculation/estimation principle, and data used in data estimation. ${ }^{\mathrm{a}}$ The authors expect that there will be no emissions from the upscaled processes. ${ }^{\mathrm{b}}$ The name of the simulation software used in the LCA study can be found in Table 1 in Online Resource 1

\subsubsection{Upscaling framework}

Based on the review results, we developed a framework for the upscaling of emerging technologies in ex ante LCA. This framework is comprised of three main steps: (1) projected technology scenario definition, (2) preparation of a projected LCA flowchart, and (3) projected data estimation. We distinguished between projected technology scenario definition, preparation of a projected LCA flowchart, and projected data estimation because we consider them to be three separate steps in the upscaling, as they involve different types of expertise, decisions, choices, and assumptions. Figure 2 shows a schematic representation of the framework.

Projected technology scenario definition The first step typically requires technology expertise and not so much LCA knowledge. A technology expert develops a scenario of what a hypothetical upscaled technology may look like in the future. The expert has to decide on required process operation conditions and installations for the hypothetical upscaled technology and can design a process flow diagram.

Preparation of a projected LCA flowchart The next step mostly involves LCA expert knowledge. The results of the first step are handed over to the LCA practitioner. The LCA expert develops an LCA flowchart (involving a technology expert) by, for example, aggregating installations into unit processes and defining function, functional unit, reference flow, system boundaries, unit processes, etc.

Projected data estimation Finally, data need to be estimated for the unit processes defined in the LCA flowchart by using
Fig. 2 The framework showing the upscaling steps in ex ante LCA

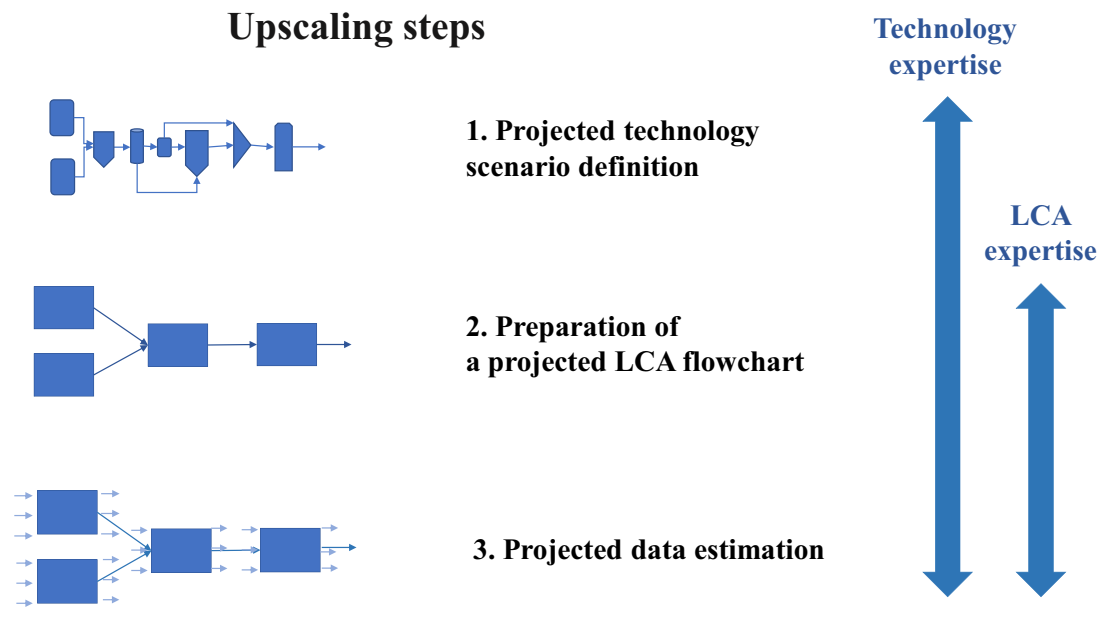


data estimation methods. Typically, data estimation is performed by an LCA expert but also involves technology experts, e.g., for applying process simulation software and for double checking assumptions and final data. The data estimation step is performed in iteration with the second step, "Preparation of a projected LCA flowchart."

In summary, we define an upscaling method as a procedure that projects how a new technology currently available at a lower TRL may look and function at a higher TRL; upscaling should ideally be performed in three steps: (1) projected technology scenario definition, (2) preparation of a projected LCA flowchart, and (3) projected data estimation.

\subsection{Application of the framework in the reviewed studies}

This section discusses whether reviewed ex ante LCA studies followed the steps defined in the framework. The review results showed that most studies (17 out of 18) performed technology scenario definition (the first step of the framework) (Online resource 2). In one study, the "technology scenario definition" step was not explicitly addressed (Cuéllar-Franca et al. 2016). It is unclear whether the study defined a technology scenario: maybe the authors implicitly defined a technology scenario but did not report on that or skipped the technology scenario definition step.

In 15 out of 18 studies, it remained unclear whether technology experts were involved in the technology scenario definition or not. We assume that some studies involved technology experts in the upscaling process without mentioning it, since the studies used simulation software and made assumptions on the process operation parameters, which requires knowledge of technology and engineering. We recommend that technology experts be involved in the technology scenario definition step and that the studies report on how they defined a technology scenario, i.e., describe how they came up with the scenario and describe the process operation conditions and installations they defined for an upscaled technology.

It appeared that $50 \%$ of the studies did not design full LCA flowcharts (9 out of 18). Some studies prepared simplified process diagrams and used those diagrams for the data estimation step. We recommend that LCA experts prepare full LCA flowcharts and present those as part of their reporting to be transparent on assumptions and on the translation of technology expert scenarios into LCA flowcharts.

The review results showed that the data estimation methods used in ex ante LCA were similar to the data estimation methods applied in ex-post LCA: plant data, process simulation, manual calculations, MSMs, and using proxy.

Ex ante LCA studies in the present review estimated data for a separate unit process of the LCA flowchart or simple process diagram and used a mix of data estimations methods in the upscaling of a new technology. Data estimation was mostly performed using manual calculations (10 out of 18 studies). This could be due to the fact that most studies assessed chemical technologies and the data (equations specifically derived for chemical processes and the data of process operation conditions) were readily available for manual calculations. Process simulation was used in a smaller number of studies than manual calculations (6 out of 18 studies). The reason could be that process simulation is more challenging than manual calculation. For example, process simulation requires more comprehensive data (more detailed data of process operation conditions) than manual calculations, and, in addition, it requires access to simulation software, expertise in process design, and skills in software use. In 7 out of 18 studies, data were estimated using data from different technologies, and only 1 study used MSMs, which is most likely due to the fact that MSMs have only recently been introduced for data estimation in LCA.

Several studies did not include any estimations of emissions and natural resource use. Emissions could probably be upscaled from lab or pilot scale to commercial scale, but most lab-scale or pilot-scale studies did not report estimations of environmental emissions. The reason for that could be that the aim of these studies was to develop proof of concept at lab scale or to test a new process at pilot scale, and hence these studies did not focus on the estimation of emissions. Another reason could be that it is unclear how these emissions could be estimated because it is unclear what kind of chemical emissions could be formed during the process, as chemical species tend to react with each other, resulting in other chemical configurations. However, it is essential to estimate emissions in LCA of emerging technologies, and it is advisable to perform a review study on how the emission data could be estimated for future commercial-scale technologies, see, e.g., Ma et al. (2019).

It should be noted that some methods have inherent constraints limiting their applicability to specific technologies; for example, stoichiometry (manual calculations) and MSMs can only be used for chemical technologies. However, MSMs are based on neural networks, and in theory, neural networks can be used for data estimation for technologies from different application domains. Neural networks have probably been used in data estimation in ex-post LCA, but only MSMs were found to be used in ex ante LCA.

Based on our review findings, we summarized the key characteristics of data estimation methods used in ex ante LCA in Table 3. As discussed before, we found that data estimation methods used in ex ante LCA can be classified in the same classes as the data estimation methods applied in expost LCA (Parvatker and Eckelman 2019). It was noted that the data estimation methods used in ex ante LCA had characteristics that were similar to those of the data estimation methods used in ex-post LCA described by Parvatker and Eckelman (2019). 
Table 3 Summary of key characteristics of data estimation methods used for upscaling in ex ante LCA

\begin{tabular}{|c|c|c|c|c|c|c|}
\hline $\begin{array}{l}\text { Upscaling } \\
\text { method }\end{array}$ & Results obtained & Tools and data needed & Expertise required & Advantages & Disadvantages & $\begin{array}{l}\text { Accuracy }^{\mathrm{b}} \\
\text { (Parvatker } \\
\text { and } \\
\text { Eckelman } \\
\text { 2019) }\end{array}$ \\
\hline $\begin{array}{l}\text { Process } \\
\quad \text { simula- } \\
\text { tion }\end{array}$ & $\begin{array}{l}\text { Material/energy } \\
\text { inputs and } \\
\text { outputs, } \\
\text { elementary } \\
\text { flows }^{\mathrm{a}}\end{array}$ & $\begin{array}{l}\text { Simulation software, } \\
\text { data on process } \\
\text { operation conditions }\end{array}$ & $\begin{array}{l}\text { 1. Technology knowledge } \\
\text { 2. Process design skills } \\
\text { 3. Skills in software use } \\
\text { 4. Engineering knowledge } \\
\text { (e.g., chemical } \\
\text { engineering in case of } \\
\text { chemical technologies) }\end{array}$ & $\begin{array}{l}\text { 1. Calculations done by } \\
\text { software are fast }\end{array}$ & $\begin{array}{l}\text { 1. Process design } \\
\text { can be time } \\
\text { consuming } \\
\text { 2. Can be } \\
\text { expensive (a } \\
\text { license for } \\
\text { software may } \\
\text { be needed) } \\
\text { 3. Requires } \\
\text { detailed data on } \\
\text { process } \\
\text { conditions } \\
\text { 4. Interpretation } \\
\text { of simulation } \\
\text { data might be } \\
\text { challenging }\end{array}$ & 1 \\
\hline $\begin{array}{l}\text { Manual } \\
\text { calcula- } \\
\text { tions }\end{array}$ & $\begin{array}{l}\text { Material/energy } \\
\text { inputs and } \\
\text { outputs, } \\
\text { elementary } \\
\text { flows }\end{array}$ & $\begin{array}{l}\text { Equations, process } \\
\text { operation conditions, } \\
\text { yields of conversions, } \\
\text { efficiency values }\end{array}$ & $\begin{array}{l}\text { 1. Technology knowledge } \\
\text { 2. Engineering knowledge } \\
\text { (e.g., chemical } \\
\text { engineering in case of } \\
\text { chemical technologies) }\end{array}$ & $\begin{array}{l}\text { 1. Inputs and outputs for } \\
\text { most processes (e.g., } \\
\text { stirring, filtration) can be } \\
\text { calculated manually }\end{array}$ & $\begin{array}{l}\text { 1. Time-consumi- } \\
\text { ng } \\
\text { 2. Requires data } \\
\text { on process } \\
\text { conditions }\end{array}$ & 2 \\
\hline $\begin{array}{l}\text { Molecular } \\
\text { Structure } \\
\text { Models }\end{array}$ & $\begin{array}{l}\text { Material inputs } \\
\text { and outputs, } \\
\text { elementary } \\
\text { flows }\end{array}$ & $\begin{array}{l}\text { Chemical structure of } \\
\text { molecules }\end{array}$ & $\begin{array}{l}\text { 1. Basic knowledge in } \\
\text { chemistry }\end{array}$ & $\begin{array}{l}\text { 1. Data estimation is fast } \\
\text { and easy to perform } \\
\text { 2. Data estimation is } \\
\text { possible even if most of } \\
\text { the data is lacking }\end{array}$ & $\begin{array}{l}\text { 1. It is applicable } \\
\text { only to } \\
\text { chemical } \\
\text { technologies }\end{array}$ & 3 \\
\hline $\begin{array}{l}\text { Use of } \\
\text { proxy }\end{array}$ & $\begin{array}{l}\text { Material/energy } \\
\text { inputs and } \\
\text { outputs, } \\
\text { elementary } \\
\text { flows }\end{array}$ & $\begin{array}{l}\text { Data for a proxy } \\
\text { technology }\end{array}$ & $\begin{array}{l}\text { 1. Technology knowledge } \\
\text { 2. Engineering knowledge }\end{array}$ & $\begin{array}{l}\text { 1. Data estimation is fast } \\
\text { and easy to perform } \\
\text { 2. Data estimation is } \\
\text { possible even if most of } \\
\text { the data is lacking }\end{array}$ & $\begin{array}{l}\text { 1. Data for a } \\
\text { similar } \\
\text { technology } \\
\text { should be } \\
\text { found }\end{array}$ & 4 \\
\hline
\end{tabular}

The key characteristics of data estimation methods used in ex ante LCA were similar to the characteristics given by Parvatker and Eckelman (2019) for the methods used in ex-post LCA

${ }^{\mathrm{a}}$ Elementary flows $=$ emissions and natural resource use. ${ }^{\mathrm{b}}$ Accuracy — the accuracy of the LCA results obtained after data estimation. (1) The most accurate data estimation method and (4) the least accurate data estimation method

\subsection{Decision tree}

Based on the literature review results, we developed a decision tree that provides recommendations for upscaling of an emerging technology in ex ante LCA (Fig. 3). In particular, the decision tree identifies the steps that should be taken when developing upscaling scenarios including projected technology scenario definition, preparation of a projected flowchart, and the choice of a method for projected data estimation based on the availability of the data, the accuracy of the LCA results obtained after upscaling (the methods listed at the top of the decision tree result in more accurate LCA results than the methods listed at the bottom), and the application domain. For data estimation, the same hierarchy in terms of data availability and accuracy can be used as for ex-post LCA (Parvatker and Eckelman 2019).

The present review only captures upscaling methods that have already been applied in ex ante LCA. Methods that have not yet been applied or could not be applied in ex ante LCA were not included in the review.

\section{Conclusions and recommendations}

This paper reviewed upscaling methods applied in ex ante LCA based on two sets of predefined criteria aiming to answer three questions: 


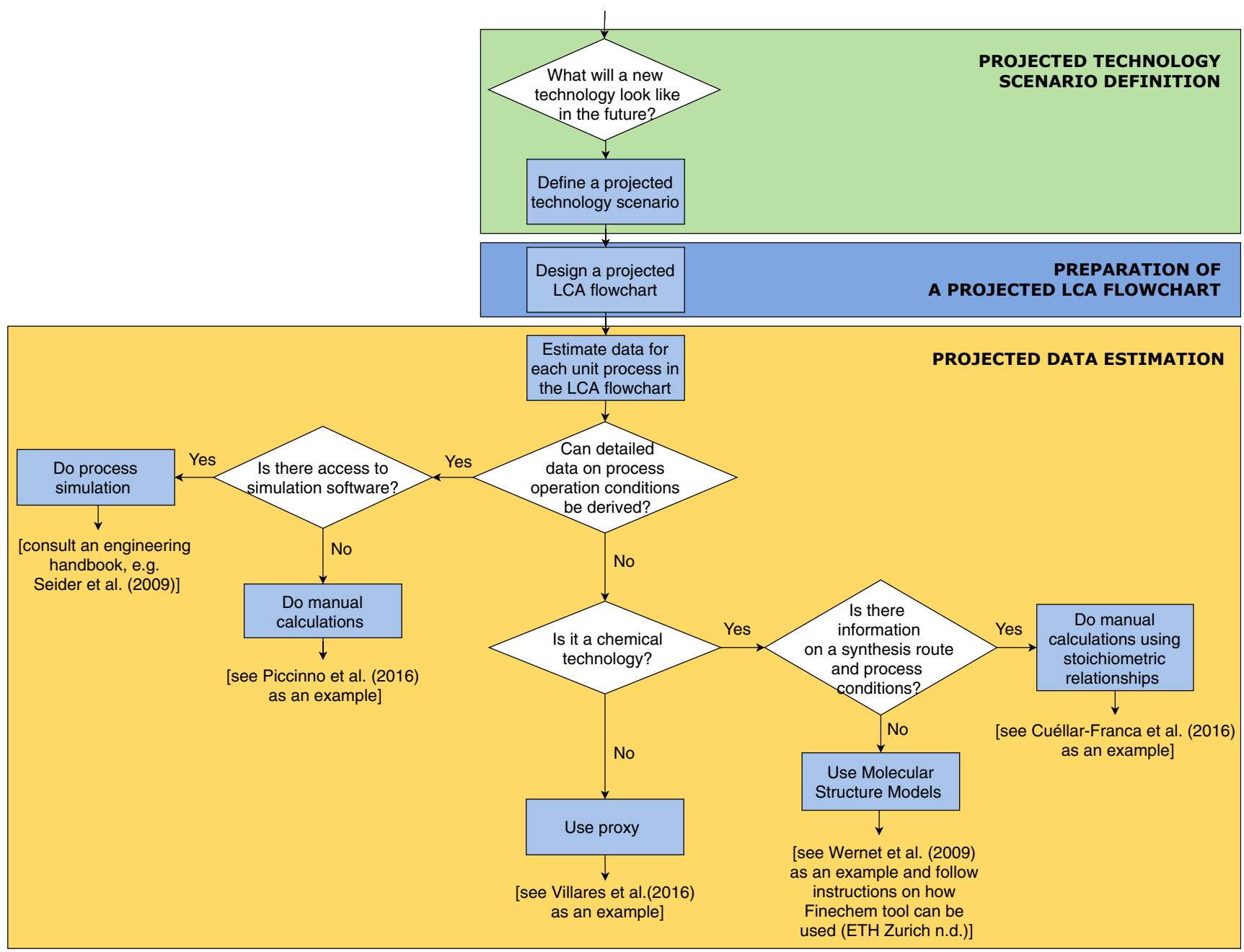

Fig. 3 Decision tree for upscaling of an emerging technology in ex ante LCA

1. Which upscaling methods have already been applied in ex ante LCA, and what are their key characteristics and methodological principles?

2. What steps are involved in the upscaling of emerging technologies in ex ante LCA?

3. Which recommendations can be given to practitioners of ex ante LCA regarding upscaling?

Regarding the first question, our findings show that most studies reported what a hypothetical upscaled technology would look like in the future. In most studies, the authors did not describe in detail how the hypothetical upscaled technology was designed. For instance, they did not report if technology experts were involved in the upscaling. We recommend that upscaling in ex ante LCA is performed in cooperation by technology experts from different fields, such as technology developers, LCA experts, and engineers.

All studies described how they estimated data. In general, four data estimation methods were used: process simulation, manual calculations, MSMs, and using data from proxy technology. Remarkably, in most studies data was estimated using manual calculations, and only one study used MSMs. The use of MSMs for data estimation in LCA is currently being explored, which probably explains why MSMs have not been reported very often as being used in ex ante LCA. Some studies estimated data using a mix of methods. It is unclear whether a mix of data estimation methods would lead to more accurate results than the use of only one method. Some methods have limitations in their applicability to specific technologies; for example, stoichiometry (manual calculations) and MSMs can only be used for chemical technologies.

None of the reviewed studies reported on the accuracy of the upscaling results, i.e., the results of ex ante LCA were not validated after the implementation of the new technology at industrial scale. We recommend validation of ex ante LCA results once the technology is operating at full scale to check the accuracy of the upscaling methods.

Furthermore, our findings show that studies upscaled different kinds of technologies from different application 
domains, such as chemistry, waste treatment, energy, food, and the building sector. Most studies performed upscaling for chemical and waste treatment technologies. All studies reported on how they estimated energy and material inputs and outputs, but not all of them reported on how they estimated emissions. Reporting on how emissions were estimated is important in LCA, and we recommend LCA practitioners to report on that. All studies described technologies by using the terms "lab-scale," "pilot-scale," "industrial-scale," or "fullscale," and some studies mentioned the expected production capacity of the upscaled technology at pilot or industrial scale (Online Resource 2), but none of them specified TRLs. We recommend that LCA experts report on TRLs, since TRLs provide a much clearer indication of the maturity level of a technology than the general terms "lab-scale," "pilot-scale," "industrial scale," or "full-scale" and production capacities.

Regarding the second question, we developed a framework based on our review results that can be used in the upscaling of emerging technologies in ex ante LCA. The framework consists of three main steps: (1) projected technology scenario definition, (2) preparation of a projected LCA flowchart, and (3) projected data estimation. Each step involves different types of expertise, decisions, choices, and assumptions. In the first step, a technology expert develops a scenario resembling a specific upscaled emerging technology at pilot scale (TRL 6-8) or at industrial scale (TRL 9). The same technology expert may also specify required process operation conditions, installations, etc. for a technology at higher TRL. Then, in the second step, an LCA expert prepares LCA flowchart by using the results of the technology scenario definition step. In the third step, the LCA expert estimates data for each unit process defined in the LCA flowchart.

With regard to the third question, we conclude that there is no standard approach for upscaling in ex ante LCA. That is why there is no consensus among LCA practitioners on how upscaling should be done. Thus, we developed a decision tree that recommends which steps should be followed in the upscaling procedure and which methods should be used for data estimation based on the availability of the data, the accuracy of the results obtained after data estimation, and the application domain. LCA practitioners can use this decision tree in their ex ante LCA case studies, but they should also keep in mind that this decision tree gives a general overview of upscaling procedures and that some alterations can be necessary for upscaling in a particular case study.

Acknowledgments This research was carried out within the project Carbon4PUR, which received funding from the European Union's Horizon 2020 research and innovation program under grant agreement No 768919. The European Commission is neither responsible nor liable for the content of this document. The authors would like to thank Martin Machat at Covestro and Daniel Roth at RWTH Aachen (RheinischWestfälische Technische Hochschule Aachen) for the manuscript revision.
Statement of author contributions Jeroen Guinée developed the initial idea of the article. Natalya Tsoy performed literature search, review, data analysis, and was the main author of all text. All authors read, commented, developed structure and text proposals, and approved the final manuscript.

\section{Compliance with ethical standards}

Conflict of interest The authors have no conflict to declare

Open Access This article is licensed under a Creative Commons Attribution 4.0 International License, which permits use, sharing, adaptation, distribution and reproduction in any medium or format, as long as you give appropriate credit to the original author(s) and the source, provide a link to the Creative Commons licence, and indicate if changes were made. The images or other third party material in this article are included in the article's Creative Commons licence, unless indicated otherwise in a credit line to the material. If material is not included in the article's Creative Commons licence and your intended use is not permitted by statutory regulation or exceeds the permitted use, you will need to obtain permission directly from the copyright holder. To view a copy of this licence, visit http://creativecommons.org/licenses/by/4.0/.

\section{References}

Arvidsson R, Molander S (2017) Prospective life cycle assessment of epitaxial graphene production at different manufacturing scales and maturity. J Ind Ecol 21:1153-1164. https://doi.org/10.1111/ jiec. 12526

Arvidsson R, Tillman AM, Sandén BA, Janssen M, Nordelöf A, Kushnir D, Molander S (2018) Environmental assessment of emerging technologies: recommendations for prospective LCA. J Ind Ecol 22: 1286-1294. https://doi.org/10.1111/jiec.12690

Buyle M, Audenaert A, Billen P, Boonen K, Van Passel S (2019) The future of ex-ante LCA? Lessons learned and practical recommendations. Sustainability (Switzerland) 11. https://doi.org/10.3390/ su11195456

Cossutta M, McKechnie J, Pickering SJ (2017) A comparative LCA of different graphene production routes. Green Chem 19:5874-5884. https://doi.org/10.1039/c7gc02444d

Cucurachi S, Van Der Giesen C, Guinée J (2018) Ex-ante LCA of emerging technologies. Procedia CIRP 69:463-468. https://doi.org/10. 1016/j.procir.2017.11.005

Cuéllar-Franca RM, García-Gutiérrez P, Taylor SFR, Hardacre C, Azapagic A (2016) A novel methodology for assessing the environmental sustainability of ionic liquids used for $\mathrm{CO}_{2}$ capture. Faraday Discuss 192:283-301. https://doi.org/10.1039/c6fd00054a

European Association of Research and Technology (2014) The TRL scale as a Research \& Innovation Policy Tool, EARTO Recommendations. Earto. https://www.earto.eu/wp-content/ uploads/The_TRL_Scale_as_a_R_I_Policy_Tool_-_EARTO_ Recommendations_-_Final.pdf

ETH Zurich (n.d.) Finechem Tool. https://emeritus.setg.ethz.ch/research/ downloads/software\%2D\%2D-tools/fine-chem.html. Accessed 11 January 2020

Fernández-Dacosta C, Posada JA, Kleerebezem R, Cuellar MC, Ramirez A (2015) Microbial community-based polyhydroxyalkanoates (PHAs) production from wastewater: techno-economic analysis and ex-ante environmental assessment. Bioresour Technol 185: 368-377. https://doi.org/10.1016/j.biortech.2015.03.025

Gavankar S, Suh S, Keller AA (2015) The role of scale and technology maturity in life cycle assessment of emerging technologies: a case 
study on carbon nanotubes. J Ind Ecol 19:51-60. https://doi.org/10. $1111 /$ jiec. 12175

González-García S, Argiz L, Míguez P, Gullón B (2018a) Exploring the production of bio-succinic acid from apple pomace using an environmental approach. Chem Eng J 350:982-991. https://doi.org/10. 1016/j.cej.2018.06.052

González-García S, Morales PC, Gullón B (2018b) Estimating the environmental impacts of a brewery waste-based biorefinery: bioethanol and xylooligosaccharides joint production case study. Ind Crop Prod 123:331-340. https://doi.org/10.1016/j.indcrop.2018.07. 003

Guinée J, Cucurachi S, Henriksson P, Heijungs R (2018) Digesting the alphabet soup of LCA. Int J Life Cycle Assess 23(7):1507-1511. https://doi.org/10.1007/s11367-018-1478-0

Hellweg S, Canals LMI (2014) Emerging approaches, challenges and opportunities in life cycle assessment. Science. 344:1109-1113. https://doi.org/10.1126/science. 1248361

Hetherington AC, Borrion AL, Griffiths OG, McManus MC (2014) Use of LCA as a development tool within early research: challenges and issues across different sectors. Int J Life Cycle Assess 19:130-143. https://doi.org/10.1007/s11367-013-0627-8

Hornik K, Stinchcombe M, White H (1989) Multilayer feedforward networks are universal approximators. Neural Netw 2:359-366. https:// doi.org/10.1016/0893-6080(89)90020-8

Khojasteh Salkuyeh Y, Saville BA, MacLean HL (2017) Technoeconomic analysis and life cycle assessment of hydrogen production from natural gas using current and emerging technologies. Int $\mathrm{J}$ Hydrog Energy 42:18894-18909. https://doi.org/10.1016/j. ijhydene.2017.05.219

Ma L, Guan D, Wang F, Deng Y, Yuan C (2019) Environmental sustainability of liquid-based chemical synthesis of Si nanotube as anode for Lithium-ion batteries. ACS Appl Nano Mater 2:5546-5552. https://doi.org/10.1021/acsanm.9b01119

Mankins J (1995) Technology readiness levels - a white paper. Advanced Concepts Office, Office of Space Access and Technology, National Aeronautics and Space Administration (NASA), Washington, DC

Mattick CS, Landis AE, Allenby BR, Genovese NJ (2015) Anticipatory life cycle analysis of in vitro biomass cultivation for cultured meat production in the United States. Environ Sci Technol 49(19):1194111949. https://doi.org/10.1021/acs.est.5b01614

Mazzoni R, Cesari C, Zanotti V, Lucarelli C, Tabanelli T, Puzzo F et al (2019) Catalytic biorefining of ethanol from wine waste to Butanol and higher Alcohols: Modeling the Life Cycle Assessment and Process Design. ACS Sustain Chem Eng. https://doi.org/10.1021/ acssuschemeng.8b02959

Moni SM, Mahmud R, High K, Carbajales-Dale M (2020) Life cycle assessment of emerging technologies: a review. J Ind Ecol 24:52 63. https://doi.org/10.1111/jiec.12965

Muñoz I (2019) 2.-0 LCA consultants, Aalborg, Denmark. Personal communication

Muñoz I, Portillo F, Rosiek S, Batlles FJ, Martínez-Del-Río J, Acasuso I et al (2019) Prospective environmental and economic assessment of solar-assisted thermal energy recovery from wastewater through a sequencing batch biofilter granular reactor. J Clean Prod 212:1300 1309. https://doi.org/10.1016/j.jclepro.2018.12.074

Pallas G, Peijnenburg WJGM, Guinée JB, Heijungs R, Vijver MG (2018) Green and clean: reviewing the justification of claims for nanomaterials from a sustainability point of view. Sustainability (Switzerland) 10. https://doi.org/10.3390/su10030689
Parvatker AG, Eckelman MJ (2019) Comparative evaluation of chemical life cycle inventory generation methods and implications for life cycle assessment results. ACS Sustain Chem Eng 7:350-367. https://doi.org/10.1021/acssuschemeng.8b03656

Piccinno F, Hischier R, Seeger S, Som C (2016) From laboratory to industrial scale: a scale-up framework for chemical processes in life cycle assessment studies. J Clean Prod 135:1085-1097. https://doi. org/10.1016/j.jclepro.2016.06.164

Piccinno F, Hischier R, Seeger S, Som C (2018) Predicting the environmental impact of a future nanocellulose production at industrial scale: application of the life cycle assessment scale-up framework. J Clean Prod 174:283-295. https://doi.org/10.1016/j.jclepro.2017. 10.226

Rinaldi C, Masoni P, Salvati F, Tolve P (2015) Life cycle assessment of innovative technology for energy production from automotive shredder residue. Integr Environ Assess Manag 11:435-444. https://doi.org/10.1002/ieam.1659

Salas DA, Ramirez AD, Ulloa N, Baykara H, Boero AJ (2018) Life cycle assessment of geopolymer concrete. Constr Build Mater 190:170 177. https://doi.org/10.1016/j.conbuildmat.2018.09.123

Sampaio APC, de Sá M, de Sousa Filho M, Castro AL, de Figueirêdo MC (2017) Life cycle assessment from early development stages: the case of gelatin extracted from tilapia residues. Int J Life Cycle Assess 22:767-783. https://doi.org/10.1007/s11367-016-1179-5

Schulze R, Abbasalizadeh A, Bulach W, Schebek L, Buchert M (2018) An ex-ante LCA study of rare earth extraction from NdFeB magnet scrap using molten salt electrolysis. J Sustain Metall 4(4):493-505. https://doi.org/10.1007/s40831-018-0198-9

Seider WD, Seader JD, Lewin DR, Widagdo S (2009) Product and process design principles. Synthesis, analysis, and evaluation, 3rd edn. John Wiley \& Sons, Inc, Hoboken

Shibasaki M, Warburg N, Eyerer P (2006) Upscaling effect and life cycle assessment. Lce 2006

Simon B, Bachtin K, Kiliç A, Amor B, Weil M (2016) Proposal of a framework for scale-up life cycle inventory: a case of nanofibers for lithium iron phosphate cathode applications. Integr Environ Assess Manag 12:465-477. https://doi.org/10.1002/ieam.1788

Thonemann N, Schulte A, Maga D (2020) How to conduct prospective life cycle assessment for emerging technologies? A systematic review and methodological guidance. Sustainability (Switzerland) 12. https://doi.org/10.3390/su12031192

Van der Giesen C, Cucurachi S, Guinée J, Kramer G, Tukker A (2020) A critical view on the current application of LCA for new technologies and recommendations for improved practice. J Clean Prod 259: 120904. https://doi.org/10.1016/j.jclepro.2020.120904

Villares M, Ișildar A, Mendoza Beltran A, Guinee J (2016) Applying an ex-ante life cycle perspective to metal recovery from e-waste using bioleaching. J Clean Prod 129:315-328. https://doi.org/10.1016/j. jclepro.2016.04.066

Wender BA, Foley RW, Hottle TA, Sadowski J, Prado-Lopez V, Eisenberg DA, Laurin L, Seager TP (2014) Anticipatory life-cycle assessment for responsible research and innovation. J Responsible Innov 1:200-207. https://doi.org/10.1080/23299460.2014.920121

Wernet G, Papadokonstantakis S, Hellweg S, Hungerbühler K (2009) Bridging data gaps in environmental assessments: modeling impacts of fine and basic chemical production. Green Chem 11:1826. https:// doi.org/10.1039/b905558d

Publisher's note Springer Nature remains neutral with regard to jurisdictional claims in published maps and institutional affiliations. 